\title{
В.Г. ХАРИТОНОВА
}

\section{ИНСТИТУТ СЕЛЬСКИХ СТАРОСТ В ЧУВАШИИ: ИСТОРИЯ ФОРМИРОВАНИЯ И ДЕЯТЕЛЬНОСТИ}

\begin{abstract}
Ключевые слова: Чувашская Республика, институт сельских старост, сельское сообщество, государственная политика на селе, сельское самоуправление.
\end{abstract}

В статье рассматриваются вопросы формирования института старост и роль сельских старост в функционировании системы местного самоуправления в современной Чувашии. Для региона, где доля сельского населения в общей численности жителей достаточно высока, изучение данной темы востребовано. В статье кратко освещены основные аспекты развития сельского сообщества и государственной политики на селе. Проведен анализ разработки данной темы в отечественной и региональной историографии. Основное внимание обращено на историю формирования института сельских старост, характеристику правового статуса, функций сельских старост, показаны основные формы их деятельности. Появление сельских старост и организация их деятельности в 1990-е ге. были вызваны необходимостью представлять интересы населения в органах власти разного уровня. На первых этапах их фрункционирование было инициировано самими жителями сел и деревень. В последующем региональные власти и муниципалитеты также стали заниматься вопросами организации и правового регулирования деятельности сельских старост. Законодательное оформление института старост сельских поселений на государственном и региональном уровне произошло в 2018 г. Практическая деятельность сельских старост Чувашии охватывает большинство вопросов развития и благоустройства сельских территорий, они являются основными помощниками местных органов власти и гарантией общественного территориального самоуправления на селе. Одновременно отмечено отчуждение сельских жителей от решения вопросов сельского общества, для этого использованы материалы социологического опроса населения. Показано, что формирование института старост и регулирование их деятельности в республике происходили на основе практической работы сельских старост, анализе опыта взаимодействия с органами местного самоуправления и с учетом опыта других регионов. На современном этапе взаимодействие с органами власти республики разного уровня налаживается. Эмпирическую базу статьи составили официальные документы, законодательные акты, материалы СМИ, результаты опросов населения.

На современном этапе сельское население и село играют немаловажную роль в развитии Чувашской Республики. Исторически сложилось так, что Чувашия вплоть до начала 1980-х гг. оставалась аграрно-индустриальным регионом, аграрный сектор и сегодня является значимой отраслью экономики. Некоторые особенности, связанные с традиционным сельским образом жизни, характерны для общества. Прежде всего, это достаточно высокая доля сельского населения в республике: $36,6 \%$ на 1 января 2020 г., и это несмотря 
на более быстрые темпы сокращения сельского населения в сравнении с общереспубликанскими данными. С 2010 г. по 2019 г. численность сельского населения сократилась на 78, 4 тыс. человек, в последние пять лет с 2015 г. по 2020 г. на 32,9 тыс. человек [20. С. 29-30; 29. С. 43]. В то же время экономика большинства районов зависит от состояния сферы АПК. В последние годы одним из приоритетных направлений государственной политики на селе рассматривается устойчивое развитие сельских территорий. Начиная с 2020 г. в рамках государственной программы Российской Федерации «Комплексное развитие сельских территорий» реализуется новое направление реализация проектов комплексного развития сельских территорий (сельских агломераций), предусматривающих строительство, реконструкцию, модернизацию, капитальный ремонт объектов социально-культурной сферы, объектов газификации, водоснабжения, энергообеспечения в сельской местности. Одним из приоритетных подходов для достижения целей и решения задач устойчивого развития сельских территорий в документе обозначены развитие и поддержка деятельности сельских старост [14].

Для реализации поставленных задач важно, чтобы сельское сообщество было готово к новым изменениям, а сельское население - к активному сотрудничеству и взаимодействию. В годы реформ в аграрной сфрере четко проявились тенденции отчуждения селян от власти, сужения структуры, содержания и форм реализации ресурсного потенциала жизненного пространства села [3. С. 55-64]. Вопросы совершенствования и оптимизации территориальной организации местного самоуправления становятся актуальными. Институт сельских старост представляет одну из форм общественной жизни сельских поселений, основной функцией старост является содействие участию населения в осуществлении местного самоуправления.

На этом фоне изучение становления института сельских старост и их роли в функционировании системы местного самоуправления в Чувашии также востребовано. В статье рассматриваются вопросы формирования института старост и роли сельских старост в развитии системы местного самоуправления в современной Чувашии. Дана характеристика правового статуса, фрункций сельских старост, показаны основные фрормы их деятельности. Эмпирическую базу статьи составили официальные документы, законодательные акты, материалы СМИ, результаты опросов населения.

В отечественной историографии разработке данной тематики посвящены исследования междисциплинарного характера. В научных статьях, посвященных вопросам функционирования института сельских старост, прежде всего обращается внимание на развитие института местного самоуправления и правовые аспекты [7-9,16]. В ряде публикаций рассматриваются становление и развитие института сельских старост в историческом аспекте $[1,17]$. Появились работы, раскрывающие региональные практики участия сельских жителей в местном самоуправлении [4, 9]. В плане актуализации деятельности сельских старост интересен опыт Владимирской области, где изданы книги-очерки о людях, занятых этой работой [5]. Подобный проект реализован в Чувашии, где на страницах газеты «Хыпар» в 2018 г. опубликован цикл статей о сельских старостах. Следует отметить, что вопросы возрождения института сельских старост на примере Чувашской Республики не получили достаточного освещения. В отдельных работах изучен исторический опыт работы института старост в селах Чувашии [6]. 
Институт сельских старост в дореволюционной России был широко развит. Государство направляло немало усилий на укрепление общественного авторитета сельских старост. По мнению исследователей, на территории Чувашского края достаточно широкое развитие получил суд сельского старосты. Сельский староста «должен был иметь огромный опыт, соблюдать морально-этические принципы: быть хорошим семьянином, уважать старшее поколение, добросовестно относиться к работе. Обычно крестьяне старались выбрать на эту должность человека, обещавшего защищать народные интересы» [6. С.98]. С установлением новых фрорм государственности и новых фрорм управления в советский период их деятельность прекратилась. Но уже в постсоветский период в ходе реализации муниципальной реформы 1990-х гг. в разных регионах России началось возрождение этого института. По данным Министерства юстиции Российской Федерации, на начало 2017 г. сельские старосты были назначены (или избраны) и осуществляли свою деятельность в 24,1 тыс. сельских населенных пунктах в 42 субъектах Российской Федерации. В частности, данный социальный институт получил распространение в Удмуртской, Чувашской республиках, Республике Башкортостан, Владимирской, Вологодской, Калининградской, Ленинградской, Нижегородской, Оренбургской, Орловской, Рязанской, Тверской, Тульской, Ульяновской и других областях [9. С. 382; 16. С. 39-41].

Появление сельских старост и организация их деятельности было инициативой снизу. Движение развивалось спонтанно и было востребовано в связи с острой необходимостью представлять интересы населения в органах власти разного уровня, прежде всего на уровне местного самоуправления. В последующем многие муниципалитеты и региональные органы управления начали поддерживать их деятельность. Одновременно им пришлось разрабатывать вопросы правового регулирования статуса сельского старосты, принятые нормативно-правовые акты при этом не отличались единообразием. Так, по данным источников, в Вологодской области институт сельских старост начал развиваться с 1994 г. Во Владимирской области в 1995 г. первый раз избрали сельских старост. В Нижегородской области в 2010 г. задумались о фрормировании института сельских старост. В Ульяновской области в 2011 г. приняли закон «О сельских старостах», в 2017 г. организовали Ассоциацию сельских старост области. В 2011-2016 гг. Ленинградская область стала пилотным регионом по развитию института сельских старост. В области для регулирования деятельности старост было принято два закона (в 2012 и 2015 гг.) [9. С. 382-383; 24. С. 12; 26. С. 12].

На государственном уровне в России институт сельских старост закреплен законом от 18 апреля 2018 г. № 83-Ф3 «О внесении изменений в отдельные акты Российской Федерации по вопросам совершенствования организации местного самоуправления», подписанным В.В. Путиным. Данным документом введен институт старосты сельского населенного пункта, а также определены порядок его назначения и полномочия. Выдвижение кандидатуры (досрочное прекращение полномочий) старосты сельского населенного пункта осуществляется на сходе граждан, решение которого утверждается представительным органом муниципального образования, в состав которого входит данный сельский населенный пункт [11].

В Чувашии институт сельских старост начал возрождаться в середине 90-х гг. XX в. В отдельных поселениях они появились еще раньше. С 1988 г., более 30 лет старостой д. Соляной в Моргаушском районе работает Г. Тимо- 
феев, в 1990 г. старостой деревни Апанасово-Тимяши Яльчикского района избран Б. Пятаков. В последующие годы избрание старост стало традиционным в селах и деревнях Чувашии [24. С. 5; 28. С. 11]. Официально статус старост сельских населенных пунктов был закреплен законом № 99 от 21 декабря 2018 г. «Об отдельных вопросах, связанных с деятельностью и статусом старосты сельского населенного пункта на территории Чувашской Республики» [12]. На момент принятия закона в Чувашии на общественных началах сельскими старостами работали более 1,7 тыс. человек [2]. Данным документом прописывались полномочия и гарантии деятельности сельских старост. Также в нем регулировались вопросы материально-технического и организационного обеспечения деятельности старосты сельского населенного пункта, выявления, поощрения и распространения примеров наиболее эффективного исполнения ими своих полномочий посредством проведения органами местного самоуправления муниципального образования конкурса «Лучший староста сельского населенного пункта», выдачи удостоверения старосты сельского населенного пункта. Согласно законодательным документам, назначать сельских старост имеют право представители органов муниципального образования по представлению схода граждан. Срок их полномочий устанавливается уставом муниципального образования и не может быть менее двух и более пяти лет [12].

Попытки регулирования деятельности сельских старост до принятия официальных законодательных актов Российской Федерации и Чувашской Республики предпринимались на уровне муниципалитетов, как и в других регионах страны. Интересен в этом плане опыт Аликовской районной администрации, которая в 2013 г. подготовила памятку для организации деятельности сельских старост района. По этому документу в своей деятельности они должны опираться на законодательные акты Российской Федерации и Чувашской Республики, Конституцию, Федеральный закон № 131 и другие нормативные акты. При подготовке этих рекомендаций изучен опыт работы сельских старост, что представляет интерес и для исследователей. Так, сельский староста должен был выполнять функции на общественных началах; входить в состав комиссий, рабочих комитетов сельской администрации; проводить сельские собрания; следить за выполнением решений общих собраний; поддерживать связь с местными учреждениями и организациями; отчитываться о своей деятельности на годичном собрании. Местным органам власти рекомендовалось информировать сельских старост о нормативных и правовых актах, принятых ими; определять меры моральной и материальной поддержки сельских старост. Основными задачами сельского старосты обозначались: предложение проектов, планов, инициатив в местные органы власти для решения вопросов развития сельских поселений; оказание поддержки местным органам власти; информирование граждан о принятых властью решениях и нормативно-правовых актах; участие в совещаниях, собраниях местной администрации, введение работы среди населения по благоустройству улиц, территории поселений, сохранению общественного порядка, взаимодействие с участковыми полицейскими и т.д. Сельский староста имел право организовывать сельские сходы. Основная задача сельских старост сводилась к защите интересов граждан, поддержке их инициативы. Деятельность старост не должна была противоречить уставу сельского поселения, в рекомендации указывалось на необходимость решения возникающих разногласий мирным путем [24. С. 6; 25. С. 12]. Таким образом, 
мы видим, что формирование института старост и регулирование их деятельности в республике происходили на основе практической работы сельских старост, анализе опыта взаимодействия с органами местного самоуправления и с учетом опыта других регионов.

Практическая деятельность старост сельских поселений направлена на организацию и осуществление мер по обеспечению общественного порядка, противопожарной безопасности, благоустройства территории населенного пункта, приусадебных участков, кладбищ, участие в решении социальных вопросов, помощь одиноким, многодетным семьям, инвалидам, ветеранам. Активное участие они принимают в организации культурных мероприятий, увековечивании памяти погибшим в Великой Отечественной войне, содействуют строительству объектов культуры, образования, здравоохранения, восстановлению и возведению церквей. Многие инициативы жителей сельских населенных пунктов Чувашии связаны с созданием благоприятных условий жизни, не хуже городских. Прежде всего их волнуют проблемы качества питьевой воды, ремонта и строительства дорог, освещения улиц. На повестке дня, особенно для молодых семей с детьми, создание мест отдыха, детских парков и т.д. Эти и другие проблемы решают сельские старосты, опираясь на запросы сельских жителей. Во всех этих случаях роль старосты велика. Это он первым направляет вопросы о нуждах населения сельской или районной администрации и первым доводит до жителей информацию от администрации. Беспокоят их вопросы экологии, отношение к родному языку, вопросы патриотического воспитания молодежи. Так, в д. Уразкасы Янтиковского района, где старостой с 2010 г. работает В. Никифоров, была построена детская площадка, часто проводятся разные конкурсы: по новогоднему оформлению домов, выращиванию цветов в палисадниках. Спортивные мероприятия для жителей села стали традиционными. Ежегодно он отчитывается перед жителями о своей деятельности. Основная забота: строительство и ремонт дорог, благоустройство улиц, кладбища, прудов [26. С. 12]. Положительно оценивают деятельность старосты Н.Ф. Васильева, избранного в 2012 г., жители д. Хыркасы Ибресинского района. Основное его качество, считают сельчане, «умение вести переговоры, владение ситуацией, решение поставленных вопросов. Первым делом по его инициативе восстановили сельские пруды, почистили, обустроили, запустили мальков рыб. Привели в порядок кладбище, памятник воинам. Н.Васильеву удалось наладить деловые отношения с местной администрацией, депутатами, предпринимателями, выходцами из села. Село сегодня развивается. Строятся новые дома, остается молодежь»[27. С. 5]. Ю. Ильин 17 лет является бессменным старостой д. Пошнары Ядринского района, он еще и депутат местного самоуправления. Глава сельской администрации В.Абрамов считает его лидером, которого уважают жители всех возрастов. Он зачинатель многих новых дел. Всегда оказывает помощь местным жителям. Ему удалось на базе сельской библиотеки возродить культурный центр, где проводятся все значимые мероприятия. Стало традицией празднование Дня деревни во время Симека. В 2011 г. построили детскую площадку, помогли земляки и друзья. Основной проблемой сельчан являлась система водоснабжения. Стараниями старосты в течение 3-4 лет удалось ее решить, провести водопровод протяженностью в 5 км. В преддверии празднования 75-летия Победы, как и во многих населенных пунктах республики, начали ремонт памятника погибшим на войне. Восстановили колхозную пожарную машину. В планах обустройство 3 родников, 
стройматериалы подготовлены. В 2008 г. он был удостоен звания «Лучший сельский староста Чувашской Республики», неоднократно награждался почетными грамотами и благодарностью [25. С. 5].

C началом реализации проектов развития общественной инфраструктуры, основанных на местных инициативах, сельские старосты активно включились в программу «инициативное бюджетирование». По планам развития сельских территорий за счет этой программы решаются первостепенные задачи. Так, в д. Чурачики Цивильского района, на стадионе «Урожай» разместили детскую игровую площадку и спортивные снаряды. На эти цели из республиканского бюджета было выделено около 1 млн руб., 37 тыс. внесли предприниматели и население. В Вурнарском районе на месте бывшей школы тоже решили построить спортивную площадку. Староста Л. Ложкина вдохновила жителей на сбор средств для строительства [24. С. 6; 28. С. 5]. Зачастую инициаторами проектов на селе выступают сельские старосты: это строительство дорог, памятников, парков, ремонт общественных зданий. В 2017 г. в республике было реализовано 103 проекта, в 2018 г. поддержано 210 проектов [10. С. 93]. Старосты сельских поселений сталкиваются и с определенными трудностями в своей деятельности. Прежде всего, это недостаточное фринансирование или полное отсутствие финансирования мероприятий и работ, в большинстве случаев часть денег на благоустройство и решение проблем деревни приходится собирать у населения. Возникают вопросы по материальному и моральному вознаграждению работы самих старост.

Анализ источников, прежде всего публикаций в средствах массовой информации, позволяет представить коллективный портрет старосты села. По мнению сельчан, староста сельский - душа села, сердце села, зеркало села. Старостой выбирают ответственного, уважаемого человека, чаще всего это бывшие руководители предприятий аграрной сферы, учреждений культуры, образования, социальной сферы или же жители, вернувшиеся на жительство в свои родные места после выхода на пенсию, большинство из них относиться к старшему поколению, среди них немало женщин. В большинстве населенных пунктов Чувашии институт сельских старост действует уже многие годы. В отдельных поселениях, к примеру, в с. Сугайкассы Канашского района, где проживает 1460 человек, практикуется работа старост на 7 улицах из 10 [23. С. 12; 26. С. 6]. По словам главы администрации Шемуршинского района В.В. Денисова: «В районе каждый населенный пункт имеет старосту, который стал неотъемлемой частью сельской жизни, гарантией общественного территориального самоуправления на селе» [15]. В Карабай-Шемуршинском сельском поселении старосту называют «отцом деревни, важной фигурой в возрождении общественного самоуправления». По мнению селян, «староста больше энтузиаст, чем просто активист. И гораздо ближе сердцу односельчан» [18]. Институт сельских старост в Чебоксарском районе существует более 16 лет. В 2014 г. в 172 селах и деревнях работали 184 старосты, средний возраст старост составил 64 года. Есть среди них и молодые, так Ю. Сорокин, которому 22 года, ведет работу в д. Мамги Чебоксарского района. Вопрос об избрании или переизбрании старост возникает часто, но не всегда находятся люди, готовые взяться за это дело $[19,27]$. По данным социологического опроса населения республики, проведенного в 2016 г., большинство населения (53,2\% опрошенных сельчан и 52,7\% горожан) отметили, что не видят пользы для себя от участия в общественных организациях и ор- 
ганах местного самоуправления. Значительна и доля тех, кто затруднился с определением своего отношения к этому вопросу, около $30 \%$ респондентов [21. С. 621].

Взаимодействие старост с муниципальными органами самоуправления, районными и республиканскими органами власти и разными государственными структурами в республике налаживается. Координационная работа проводится Советом муниципальных образований Чувашии. Для изучения опыта деятельности старост, активизации их работы, признания их заслуг почти ежегодно в республике проводятся общереспубликанские и районные слеты старост сел и деревень, практикуется обмен опытом работы, организация семинаров и ряд других мероприятий, проводится конкурс на лучшего старосту как на районном, так и на республиканском уровнях. Так решением собрания депутатов Чувашско-Сорминского сельского поселения № 141 от 1 марта 2019 г. было принято положение о проведении конкурса «Лучший староста населенного пункта». В нем указывалось, что «в целях выявления, поощрения и распространения примеров наиболее эффективного исполнения старостой своих полномочий администрацией Чувашско-Сорминского сельского поселения Аликовского района может проводиться конкурс «Лучший староста сельского населенного пункта Чувашско-Сорминского сельского поселения Аликовского района» [13].

Таким образом, современное село, как и раньше, решает комплексно ряд социально-экономических, природных и историко-культурных задач развития сельского населения и сельского сообщества в целом. В основе социального взаимодействия сельского социума лежат, прежде всего, взаимопомощь, межличностные, соседские, родственные, семейные связи. По данным социологических исследований, чувашская деревня сохраняет традиционные ценностные установки [22]. Функционирование в Чувашии института сельских старост, усовершенствование этой структуры и практическая деятельность оказывают значительное влияние развитие региона.

\section{Литература}

1. Александров Н.М. Сельские старосты в пореформенной России (права, обязанности, место в социуме) // Институты общинного самоуправления в социальной жизни многонационального крестьянства Волго-Уральского региона (XVIII в. - 20-е гг. XX в.): материалы Всерос. науч. конф. Казань: Изд-во Ин-та истории им. Ш. Марджани AH PT, 2019. C. 20-29.

2. В Чувашии узаконили сельских старост [Электронный ресурc]. URL: http://moygorod-online.ru/power/power_35931.html (дата обращения: 21.03. 2019).

3. Великий П.П., Морехина М.Ю. Адаптивный потенциал сельского социума // Социс. 2004. № 12. С. 55-64.

4. Гацко М.Ф. Возрождение института сельских старост: практика Московской области // Роль местного самоуправления в развитии государства на современном этапе: материалы III Междунар. науч.-практ. конф. М.: Гос. ун-т управления, 2018. С. 34-37.

5. Деревня моя, деревянная, дальняя: книга очерков о сельских старостах / Администрация Владимирской обл., Ком. по взаимодействию с органами федеральной гос. власти и органами местного самоуправления, Ассоц. "Совет муниципальных образований Владимирской обл."; [сост. и ред. Ю. Павлов]. Владимир, 2011.

6. Егоров Д.В. Общинная юстиция чувашского крестьянства: правовые основы, юрисдикция и методика расследования правонарушений // Актуальные вопросы истории и культуры чувашского народа: сб. ст. / сост. и науч. ред. Д.В. Егоров; ЧГИГН. Чебоксары, 2019. Вып 4. С. 92-121. 
7. Карцев Б.В., Мусинова Н.Н. Институт сельских старост как инструмент повышения инициативы и участия граждан в местном самоуправлении // Муниципальная академия. 2018. № 3. С. 118-121.

8. Курячая М.М., Громыко С.В. Институт сельских старост: предпосылки возрождения и перспективы развития // Конституционное и муниципальное право. 2020. № 2. C. $38-41$.

9. Майкова Э.Ю., Симонова Е.В. Формирование института сельских старост как фактор устойчивого развития российских муниципальных образований // XXI Уральские социологические чтения. Социальное пространство и время региона: проблемы устойчивого развития: материалы Междунар. науч.-практ. конф. Екатеринбург: Гуманитарный ун-т, 2018. С. 381-385.

10. Материалы к посланию Главы Чувашской Республики М.В. Игнатьева Государственному Совету Чувашской Республики. Чебоксары: ИП Н.А. Брындиной, 2018. $150 \mathrm{c}$.

11. О внесении изменений в отдельные акты Российской Федерации по вопросам совершенствования организации местного самоуправления: закон № 83-Ф3 от 18.04.2018 г. [Электронный ресурс] // КонсультантПлюс: сайт. URL: http://www.consultant.ru/document/cons_doc_LAW_296071 (дата обращения: 21.08.2020).

12. Об отдельных вопросах, связанных с деятельностью и статусом старосты сельского населенного пункта на территории Чувашской Республики: Закон Чувашской Республики № 99 от 21.12.2018 г. (принят государственным Советом Чувашской Республики 18.12.2018 г.) [Электронный ресурс] // Электронный фонд правовых и нормативно-технических документов: сайт. URL: http://docs.cntd.ru/document/550285666 (дата обращения: 21.08.2020).

13. Об утверждении положения о проведении конкурса «Лучший староста населенного пункта»: решение собрания депутатов № 141 от 01.03.2019 г. [Электронный ресурс] // Чувашско-Сорминское сельское поселение Аликовского района: сайт. URL: http://gov.cap.ru/laws.aspx?id= 331602\&gov_id=288 (дата обращения: 27.10.2020).

14. Об утверждении Стратегии устойчивого развития сельских территорий Российской Федерации на период до 2030 года: постановление Правительства РФ от 02.02.2015 г. № 151-р // Собрание законодательства РФ. 2015. № 6. Ст. 1014..

15. Сегодня в администрации Шемуршинского района состоялся слет старост сельских поселений [Электронный ресурc]. URL: http://gov.cap.ru/info.aspx?gov_id= 158\&id=4043746 (дата обращения: 07.03.2019).

16. Сельские старосты: за и против // Муниципальная Россия. 2017. № 1(77). C. $39-44$.

17. Семенова Л.М.Сельский староста в системе административного управления России // Актуальные вопросы истории и культуры России: сб. ст. / Башкирский государственный аграрный университет. Уфа, 2014. С. 30-37.

18. Советская Чувашия. 2009. 25 июля.

19. Советская Чувашия. 2014. 2 авг.

20. Статистический ежегодник Чувашской Республики. 2020 / Чувашстат. Чебоксары, 2020. 350 с.

21. Харитонова В.Г. Социальный капитал сельского населения и модернизация региона: на примере Чувашской Республики // Региональное измерение аграрной модернизации в России: материалы VIII Всерос. (XVI региональной) с междунар. участием конф. историков-аграрников Среднего Поволжья (г. Саранск, 16-17 сентября 2020 г.) / отв. ред. Г.А. Куршева; НИИ гуманитарных наук при Правительстве Республики Мордовия. Саранск, 2020. С. 612-626.

22. Харитонова В.Г. Ценностные предпочтения населения Чувашии: начало XXI в. // Актуальные вопросы истории и культуры чувашского народа: сб. ст. / сост. И науч. ред. Д.В. Егоров; ЧГИГН. Чебоксары, 2019. Вып 4. С. 138-152.

23. Хыпар. 2018. 6 апр.

24. Хыпар. 2018. 20 июля.

25. Хыпар. 2018. 10 авг.

26. Хыпар. 2018. 21 авг. 
27. Хыпар. 2018. 7 сент.

28. Хыпар. 2018. 9 нояб.

29. Чувашия в цифррах. 2020: крат. стат. сб. / Чувашстат. Чебоксары, 2020. 210 с.

\footnotetext{
ХАРИТОНОВА ВАЛЕНТИНА ГРИГОРЬЕВНА - КаНДидат Исторических наук, ведущий научный сотрудник, Чувашский государственный институт гуманитарных наук, Россия, Чебоксары (val1957@rambler.ru).
}

\section{Valentina G. KHARITONOVA \\ THE INSTITUTE OF VILLAGE ELDERS IN CHUVASHIA: HISTORY OF FORMATION AND ACTIVITY}

Key words: the Chuvash Republic, institute of village elders, rural community, state policy in rural areas, rural self-government.

The article deals with the issues concerning formation of the institute of the elders and the role of village elders in the functioning of the local government system in modern Chuvashia. For a region where the share of rural population in the total population is quite high, the study of this topic is in demand. The article briefly covers the main aspects in the development of the rural community and the state policy in rural areas. The analysis of this topic coverage in domestic and regional historiography is carried out. The main attention is paid to the history of forming the institute of village elders, the characteristics of the legal status and functions of village elders, and the main forms of their activities are shown. The village elders and organization of their activities in the 1990s were caused by the need to represent the interests of the population in the authorities of different levels. At the first stages, their functioning was initiated by the residents of villages themselves. Subsequently, the regional authorities and municipalities also began to deal with the organization and legal regulation of village elders' activities. Legislative formalisation of village elders' institute at the state and regional level took place in 2018. The practical activities of Chuvashia village elders cover most issues of developing and improving rural territories, they are the main assistants of local authorities and guarantee of public territorial self-government in rural areas. At the same time, alienation of rural residents from solving issues of rural society was noted, for this purpose, the materials of a sociological population survey were used. It is shown that formation of the institute of elders and regulation of their activities in the republic took place on the basis of rural elders' practical work, the analysis of the experience of interaction with local self-government bodies and taking into account the experience of other regions. At present stage, interaction with the republican authorities at various levels is being improved. The empirical basis of the article is made up of official documents, legislative acts, media materials, and the results of public surveys.

\section{References}

1. Aleksandrov N.M. Sel'skie starosty $v$ poreformennoi Rossii (prava, obyazannosti, mesto $v$ sotsiume) [Village elders in post-reform Russia (rights, duties, place in society)]. In: Instituty obshchinnogo samoupravleniya $v$ sotsial'noi zhizni mnogonatsional'nogo krest'yanstva Volgo-Ural'skogo regiona (XVIII v. - 20-e gg. XX v.): materialy Vserossiiskoi nauchnoi konferentsii. [Proc. of "Russian Scientific Conference Institutes of communal selfgovernment in the social life of the multinational peasantry of the Volga-Ural region $\left(18^{\text {th }}-\right.$ 20 s of the $20^{\text {th }}$ century)»]. Kazan, 2019, pp. 20-29.

2. $V$ Chuvashii uzakonili sel'skikh starost [In Chuvashia legalized village elders]. Available at: http://moygorod-online.ru/power/power_35931.html (Accessed 21 March 2019). 
3. Velikii P.P., Morekhina M.Yu. Adaptivnyi potentsial sel'skogo sotsiuma [Adaptive potential of rural society]. Sotsis, 2004, no. 12, pp. 55-64.

4. Gatsko M.F.Vozrozhdenie instituta sel'skikh starost: praktika Moskovskoi oblasti [Revival of the Institute of Village Elders: the practice of the Moscow region]. Rol' mestnogo samoupravleniya $v$ razvitii gosudarstva na sovremennom etape: materialy III Mezhdunar. Nauch.-prakti. konf. [Proc. of $3^{\text {rd }}$ Int. Sci. and Pract. Conf. «The role of local government in the development of the state at the present stage»]. Moscow, 2018, pp. 34-37.

5. Derevnya moya, derevyannaya, dal'nyaya: kniga ocherkov o sel'skikh starostakh [My village, wooden, distant: a book of essays about village elders]. Vladimir, 2011.

6. Egorov D.V. Obshchinnaya yustitsiya chuvashskogo krest'yanstva: pravovye osnovy, yurisdiktsiya i metodika rassledovaniya pravonarushenii [Community justice of the Chuvash peasantry: legal bases, jurisdiction and methods of investigation of offenses]. In: Aktual'nye voprosy istorii i kul'tury chuvashskogo naroda [Topical issues of the history and culture of the Chuvash people]. Cheboksary, 2019, pp. 92-121.

7. Kartsev B.V., Musinova N.N. Institut sel'skikh starost kak instrument povysheniya initsiativy $i$ uchastiya grazhdan $v$ mestnom samoupravlenii [The Institute of Village Elders as a tool for increasing the initiative and participation of citizens in local self-government]. Munitsipal'naya akademiya, 2018, no. 3, pp. 118-121.

8. Kuryachaya M.M., Gromyko S.V. Institut sel'skikh starost: predposylki vozrozhdeniya i perspektivy razvitiya [Institute of Village Elders: prerequisites for revival and prospects for development]. Konstitutsionnoe i munitsipal'noe pravo, 2020, no. 2, pp. 38-41.

9. Maikova E.Yu., Simonova E.V. Formirovanie instituta sel'skikh starost kak faktor ustoichivogo razvitiya rossiiskikh munitsipal'nykh obrazovanii [Formation of the Institute of Village elders as a factor of sustainable development of Russian municipalities]. In: XXI Ural'skie sotsiologicheskie chteniya. Sotsial'noe prostranstvo i vremya regiona: problemy ustoichivogo razvitiya: materialy Mezhdunar. nauch.-prakt. konf. [Proc. of Int. Sci. and Pract. Conf. $« 21^{\text {st }}$ Ural Sociological Readings. Social space and time of the region: problems of sustainable development»]. Ekaterinburg, 2018, pp. 381-385.

10. Materialy k poslaniyu Glavy Chuvashskoi Respubliki M.V. Ignat'eva Gosudarstvennomu Sovetu Chuvashskoi Respubliki [Materials for the address of the Head of the Chuvash Republic M. V. Ignatiev to the State Council of the Chuvash Republic]. Cheboksary, 2018, 150 p.

11. O vnesenii izmenenii $v$ otdel'nye akty Rossiiskoi Federatsii po voprosam sovershenstvovaniya organizatsii mestnogo samoupravleniya. Zakon № 83-FZ ot 18 aprelya $2018 \mathrm{~g}$. [On amendments to certain acts of the Russian Federation on improving the organization of local self-government. Law No. 83-FZ of April 18, 2018]. Available at: http://www.consultant.ru/document/cons_doc_LAW_296071/ (Accessed 21 August 2020).

12. Ob otdel'nykh voprosakh, svyazannykh s deyatel'nost'yu i statusom starosty sel'skogo naselennogo punkta na territorii Chuvashskoi Respubliki. Zakon Chuvashskoi Respubliki № 99 ot 21dekabrya $2018 \mathrm{~g}$. Prinyat gosudarstvennym Sovetom Chuvashskoi Respubliki 18 dekabrya $2018 \mathrm{~g}$. [About certain issues related to the activities and status of the headman of a rural locality in the territory of the Chuvash Republic. Law of the Chuvash Republic No. 99 of December 21, 2018 Adopted by the State Council of the Chuvash Republic on December 18, 2018]. Available at: http://docs.cntd.ru/document/550285666 (Accessed 21 August 2020).

13. Ob utverzhdenii polozheniya o provedenii konkursa «Luchshii starosta naselennogo punkta». Reshenie sobraniya deputatov № 141 ot 1 marta 2019 g. [About the approval of the regulations on holding the contest "The best village headman". Decision of the Assembly of Deputies No. 141 of March 1, 2019]. Available at: http://gov.cap.ru/ laws.aspx?id=331602\&gov_id=288 (Accessed 21 August 2020).

14. Ob utverzhdenii Strategii ustoichivogo razvitiya sel'skikh territorii Rossiiskoi Federatsii na period do 2030 goda: postanovlenie Pravitel'stva RF ot 2 fevralya $2015 \mathrm{~g}$. № 151-r [On approval of the Strategy for Sustainable Development of Rural Areas of the Russian Federation for the period up to 2030: Resolution of the Government of the Russian Federation No. 151-r of February 2, 2015]. Sobranie zakonodatel'stva RF [Collection of legislation of the Russian Federation], 2015, no. 6, St. 1014. 
15. Segodnya $v$ administratsii Shemurshinskogo raiona sostoyalsya slet starost sel'skikh poselenii [Today in the administration of the Shemurshinsky district, a meeting of the elders of rural settlements was held]. Available at: http://gov.cap.ru/info.aspx?gov_id= 158\&id=4043746 (Accessed 7 March 2019).

16. Sel'skie starosty: za i protiv [Village elders: pros and cons]. Munitsipal'naya Rossiya, 2017, no. 1(77), pp. 39-44.

17. Semenova L.M. Sel'skii starosta $v$ sisteme administrativnogo upravleniya Rossii [Village headman in the system of administrative management of Russia]. In: Aktual'nye voprosy istorii i kul'tury Rossii: sb. st. Ufa, Bashkir State Agrarian University, 2014, pp. 30-37.

18. Sovetskaya Chuvashiya, 2009, July 25.

19. Sovetskaya Chuvashiya, 2014, August 2.

20. Statisticheskii ezhegodnik Chuvashskoi Respubliki. 2020 [Statistical Yearbook of the Chuvash Republic. 2020]. Cheboksary, Chuvashstat Publ., 2020, 350 p.

21. Kharitonova V.G. Sotsial'nyi kapital sel'skogo naseleniya i modernizatsiya regiona: na primere Chuvashskoi Respubliki [Social capital of the rural population and modernization of the region: on the example of the Chuvash Republic]. In: Regional'noe izmerenie agrarnoi modernizatsii v Rossii: materialy VIII Vserossiiskoi (XVI regional'noi) s mezhdunarodnym uchastiem konferentsii istorikov-agrarnikov Srednego Povolzh'ya (g. Saransk, 16-17 sentyabrya 2020 g.) [Proc. of $4^{\text {th }}$ Rus. Sci. Conf. «Regional dimension of agrarian modernization in Russia»]. Saransk, 2020, pp. 612-626.

22. Kharitonova V.G. Tsennostnye predpochteniya naseleniya Chuvashii: nachalo $X X I V$. [Value preferences of the population of Chuvashia: the beginning of the $21^{\text {st }}$ century]. In: Aktual'nye voprosy istorii i kul'tury chuvashskogo naroda [Topical issues of the history and culture of the Chuvash people]. Cheboksary, 2019, pp. 138-152.

23. Khypar, 2018, April 6.

24. Khypar, 2018, July 20.

25. Khypar, 2018, Aug. 10.

26. Khypar, 2018, Aug. 21.

27. Khypar, 2018, Sept. 7.

28. Khypar, 2018, Nov. 9.

29. Chuvashiya $v$ tsifrakh. 2020: Krat. stat. sb. [Chuvashia in numbers. 2020. Summary of statistics ]. Cheboksary, Chuvashstat Publ., 2020, 210 p.

\footnotetext{
VALENTINA G. KHARITONOVA - Candidate of Historical Sciences, Leading Researcher, Chuvash State Institute of Humanities, Cheboksary, Russia (val1957@rambler.ru).
}

Формат цитирования: Харитонова В.Г. Институт сельских старост в Чувашии: история формирования и деятельности // Исторический поиск. - 2021. - T. 2, № 2. - C. 58-68. DOI: 10.47026/2712-9454-2021-2-2-58-68. 